\title{
Evaluation of nursing care requirements in mechanically ventilated patients
}

\author{
Gozde Kara ${ }^{1}$, Gamze Temiz ${ }^{2}$ \\ Intensive Care Department, Medical Park Hospital, Izmir, Turkey \\ ${ }^{2}$ Faculity of Hamidiye Nursing School, Health Science University, Üsküdar/İstanbul, Turkey
}

Received: 2021-11-03.

Accepted: 2022-02-10

This work is licensed under a

Creative Commons Attribution 4.0 International License

\section{J Clin Med Kaz 2022; 19(1):70-76}

\section{Corresponding author:}

Gamze Temiz.

E-mail:ngamzetemiz@gmail.com;

ORCID: 0000-0002-0681-0595

\begin{abstract}
Objective: This study aims to plan and carry out the determination of daily living activities, nursing care needs and to what extent these needs are met in patients who have been undergoing mechanical ventilation and then weaned from mechanical ventilation.

Material and methods: This research is a descriptive study planned to determine the daily living activities, nursing care needs and to what extent these needs are met in patients who have been weaned from mechanical ventilation. In this study, "What is the level of meeting the daily living activities of the patients who have been undergoing mechanical ventilation and then weaned from mechanical ventilation?", "Is there a difference between the socio-demographic characteristics of the activities of daily living?", "What are the opinions of the patients who have been undergoing mechanical ventilation and then weaned from mechanical ventilation about the nursing care needs?" sought answers to questions.

Results: The patients who participated the research were determined including into the half-dependent group cause of being the point average $11,63 \pm 3,314$ of the KATZ scale of the daily life routines. It was found statistically significant difference $(p<0,05)$ between the answer of the questions which were asked by the participating patients who needed to know about suppling with nursing care requirement. According to this: It was determined that people trust nursing care, are moderately affected by medical treatment, nutritional problems are reduced with nursing care, they receive moderate information from nurses, and they receive help from nurses for symptoms such as nausea-vomiting and pain due to illness.

In addition, it was determined that they needed to be supported in complying with care, giving explanatory information about care, being honest and communicating effectively during the therapies, paying attention to the protection of privacy, and families' participation in nursing care therapies.

Conclusion: There is a need to increase nurses' levels of knowledge about determining the care needs of patients receiving undergoing mechanical ventilation and then weaned from mechanical ventilation and meeting these needs. According to this, the knowledge of intensive care nurses should be strengthened by using visual learning techniques and simulation application methods, in addition to relevant theoretical trainings.
\end{abstract}

Key words: mechanical ventilation, patient, nursing, care, need

\section{Introduction}

Mechanical ventilation [MV] is a frequently used method to relieve respiratory muscles in patients with acute respiratory failure and to reduce the workload, especially in intensive care units $[1,2]$.

The general purposes of Mechanical Ventilation are to provide oxygen transfer to body organs and tissues until respiratory function improves, to improve hypoxia and acute respiratory acidosis, to prevent or eliminate atelectasis, to eliminate the fatigue and weakness of respiratory muscles, to reduce systemic or myocardial oxygen consumption, to decrease intracranial pressure and to stabilize the chest wall [3-5].

The patients undergoing MV who are treated in intensive care units more frequently face complications because of their critical condition. Most of these 
complications may be directly related to the application of MV, while the application of MV is an important risk factor in some of them [6].

The patients receiving treatment on the ventilator in intensive care units are fully dependent on nurses in terms of the level of care since they cannot meet self-care needs on their own. Therefore, all systems should be evaluated in detail every hour to ensure the full care of patients, eliminate physiological needs, and avoid complications due to lack of care.

As a result of the care performed by nurses by taking into account evidence-based practices, potential complications will be avoided, it will be easy for patients to wean from the ventilator, and the duration of mechanical ventilation will be reduced $[7,8]$.

Detailed determination of the care needs of the patients on mechanical ventilation is quite important and life-saving so that their bio-psycho-social needs are not ignored.

This study plan and carry out the determination of daily living activities, nursing care needs and to what extent these needs are met in patients who have been undergoing mechanical ventilation and then weaned from mechanical ventilation.

In the study, answers to the following questions were sought:

1. What is the level of meeting the daily living activities of the patients who have been undergoing mechanical ventilation and then weaned from mechanical ventilation?

2. Is there a difference between the socio-demographic characteristics of the activities of daily living?"

3. What are the opinions of the patients who have been undergoing mechanical ventilation and then weaned from mechanical ventilation about the nursing care needs?

\section{Materials and methods Design}

This study was designed as a descriptive-sectional.

\section{Participants and setting}

This study was conducted to determine the daily living activities and nursing care needs of patients weaned from mechanical ventilation and to determine to what extent these needs are met.

This descriptive study was carried out in the intensive care unit of a research and training hospital affiliated with a foundation university in Istanbul province.

All patients hospitalized in the intensive care unit between the specified dates constituted the population of the study.

The sample of the study consisted of patients over 18 years of age, who were separated from the mechanical ventilator, who agreed to participate in the study, and who had no communication problems. The score of the selected patients on the Glasgow coma scale is 15 .

The sample was determined by the convenience sampling method, which is one of the improbable sampling methods. In this context, the study was completed with 71 patients who met the inclusion criteria between May October 2017.

\section{Data collection tools}

1. Patient information form: This form includes the questions about the socio-demographic data of the patients.

2. KATZ activities of daily living scale: The permission to use the scale was obtained from Prof. Dr. It was taken from Mustafa Cankurtaran. The scale, which was developed by
Katz et al. and adapted into Turkish by Arık et al. under the supervision of Cankurtaran, measures the degree of addiction in self-care activities such as feeding, dressing, bathing, mobility, continence, and going to the toilet [8].

This scale is widely used both abroad and in our country, and it is a scale with high validity and reliability. This scale is a tool used to define functional status by measuring the patient's ability to independently perform activities of daily living. The scale, which is a Likert type, is scored between 1-3.

The individual is evaluated by giving 3 points if he/she does the activities of daily living independently, 2 points if he/she does it with help, and 1 point if he/she cannot do it at all. According to the ADL scale, 0-6 points are evaluated as a dependent, 7-12 points as semi-dependent, and 13-18 points as an independent [9].

3. Care needs questionnaire: The questionnaire developed by the researcher by using the literature data [1, 6-8] was prepared to examine the care needs of the patients. It consisted of 17 questions answered as "Yes" and "No". The questions answered as Yes were arranged in the 'Very, Moderate and Low' 3 points Likert form.

\section{Data collection}

Data were collected by the researcher by face-toface interview method in six months [May-October 2017]. Information about the disease and treatment was obtained from the patient's medical records. Data were collected using the "Patient Information Form", the "KATZ Activities of Daily Living Scale" and the" Care Needs Questionnaire".

\section{Ethical approach}

Approval [29.11.2016/55-10] was obtained from the Istanbul Bilim University Institute of Health Sciences Ethics Committee before starting the study. Institution permission was obtained for the application from the administration of the hospital where the study would be carried out. Patients whose mechanical ventilation treatment was terminated and who did not have a disability to communicate (without tracheostomy) were included in the study. The patients who volunteered to participate in the study were informed about the aim of the study and that information would not be shared with anyone, and their informed consents were obtained.

\section{Data analysis}

Data were analyzed using the statistical analysis program. Data were evaluated using descriptive statistics such as frequency distribution, arithmetic mean, standard deviation and percentage, and nonparametric tests [Kruskal-Wallis test, MannWhitney U test, Spearman correlation analysis]. The results were evaluated at a confidence interval of $95 \%$ and a significance level of $\mathrm{p}<0.05$.

\section{Results \\ Results on the KATZ activities of daily living scale}

While $50.7 \%$ of the patients stated that they had baths by standing, sitting, or wiping, $12.7 \%$ stated that they needed help to wash more than one area of their body, and $14.1 \%$ stated that they could not take a bath at all. While $46.5 \%$ of the patients stated that they completely needed help in getting and wearing their clothes, $32.4 \%$ of them stated that they needed help in going to the toilet, cleaning and preparing their belongings, $31 \%$ 
of them stated that they used a walking stick and walking tool for support while walking, $38 \%$ of them stated that they needed observation for urinary and intestinal emptying, and $25.4 \%$ of them stated that they received support on nutrition.

It was determined that the mean score of the KATZ scale was $11.63 \pm 3.314$, and accordingly, the patients were semidependent in meeting their activities of daily living.
It was determined that there was a statistically significant, positive, and low-level relationship between the ages of the patients and the KATZ activities of daily living scale scores [ rs: 0.459; $\mathrm{p}<0.05$ ] (Table 1). The KATZ Activities of Daily Living Scale scores of the patients who were civil servants were found to be statistically significantly high $[\mathrm{p}<0.05]$ (Table 1 ).

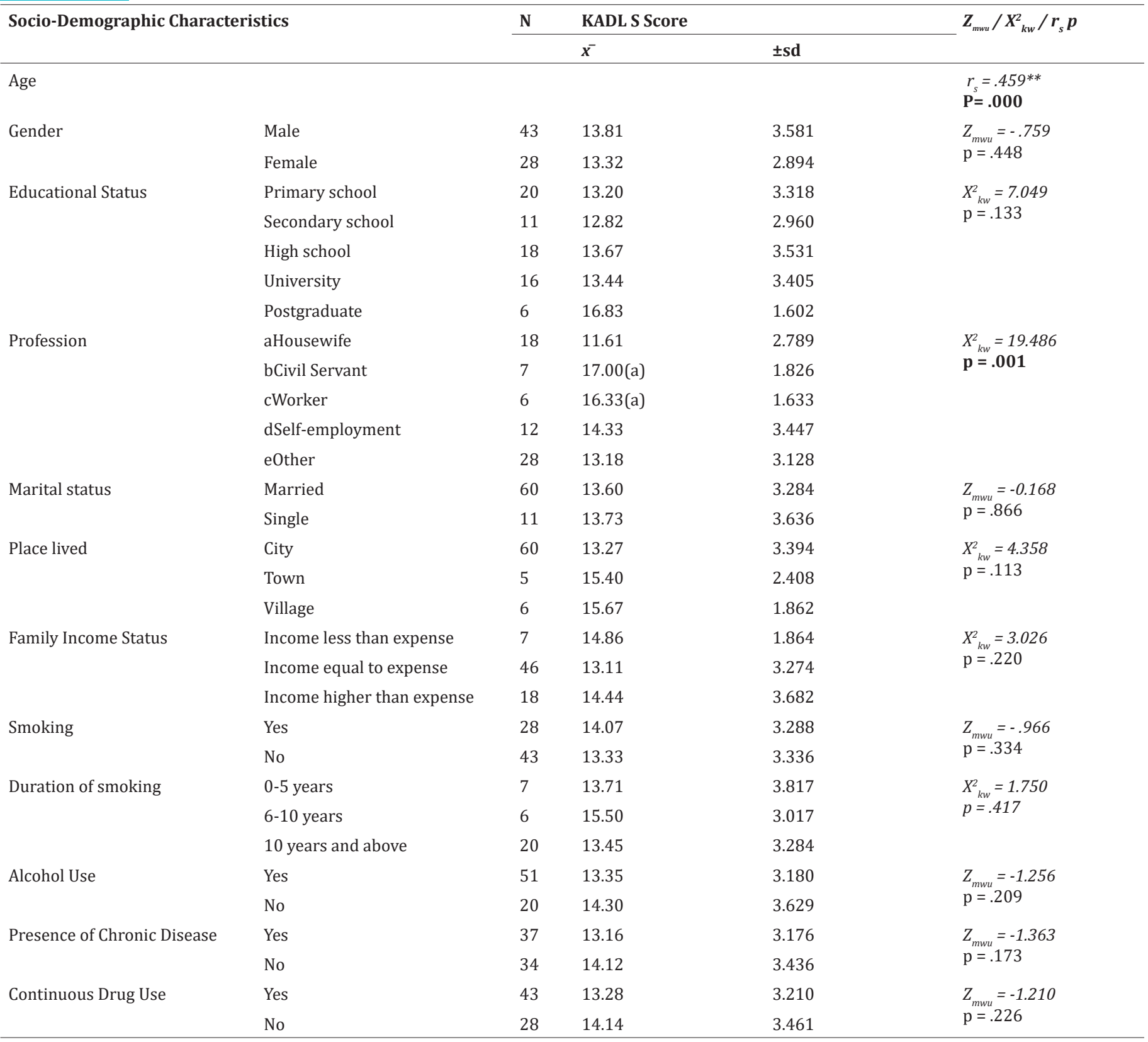

Zmwu: Mann-Whitney U Test X2kw: Kruskal-Wallis Test

rs: Spearman's correlation coefficient ${ }^{* *} \mathrm{p}<.01$

\section{Results on the care need questionnaire}

It was determined that $97.2 \%$ of the patients answered yes to the question "Can you get information about nursing care practices related to your disease from nurses?" while $95.4 \%$ of them answered yes to the question "Do you rely on the nursing care provided?".

When the distribution of the positive responses of the patients participating in the study towards nursing care as 'Very, Moderate and Low' was examined, a statistically significant difference was found between the groups. Accordingly, it was determined that the patients highly relied on nursing care, the nursing care provided moderately affected receiving medical treatment and moderately reduced the problems related to nutrition, they could moderately obtain from nurses during these practices, nursing practices were very helpful in eliminating the complaints of pain and nausea-vomiting due to disease, intraoral problems further decreased and disappeared with drug applications, nurses acted quite properly for the opinions and values while performing care practices, provided explanatory information about care, were very sincere during the practices and moderately established effective communication, was very attentive to protect the privacy and ensured families' participation in nursing care practices $[\mathrm{p}<0.05]$ (Table 2). 


\begin{tabular}{|c|c|c|c|c|c|c|c|c|}
\hline \multirow[t]{2}{*}{ Item } & \multicolumn{2}{|c|}{ Very } & \multicolumn{2}{|c|}{ Moderate } & \multicolumn{2}{|c|}{ Low } & \multirow[t]{2}{*}{$x^{2}$} & \multirow[t]{2}{*}{$\mathbf{p}$} \\
\hline & $\mathbf{N}$ & $\%$ & $\mathbf{n}$ & $\%$ & $\mathbf{n}$ & $\%$ & & \\
\hline 1. Do you rely on the nursing care provided? & 48 & 67.6 & 20 & 28.2 & - & - & 11.529 & .001 \\
\hline $\begin{array}{l}\text { 2. Did the nursing care provided ensure a decrease in adverse effects } \\
\text { you experienced due to disease, treatment? }\end{array}$ & 34 & 47.9 & 31 & 43.7 & - & - & .138 & .710 \\
\hline $\begin{array}{l}\text { 3. Did the nursing care provided make it easier for you to receive } \\
\text { medical treatment? }\end{array}$ & 36 & 50.7 & 28 & 39.4 & 1 & 1.4 & 31.046 & .000 \\
\hline $\begin{array}{l}\text { 4. Did the nursing care provided reduce your problems related to } \\
\text { nutrition? }\end{array}$ & 18 & 25.4 & 29 & 40.8 & 5 & 7.0 & 16.654 & .000 \\
\hline $\begin{array}{l}\text { 5. Can you get information about nursing care practices related to your } \\
\text { disease from nurses? }\end{array}$ & 31 & 43.7 & 33 & 46.5 & 5 & 7.0 & 21.217 & .000 \\
\hline $\begin{array}{l}\text { 6. Were nursing practices helpful in relieving the pain you experienced } \\
\text { due to your illness? }\end{array}$ & 31 & 43.7 & 30 & 42.3 & 3 & 4.2 & 23.656 & .000 \\
\hline $\begin{array}{l}\text { 6B. Did your pain complaint decrease or disappear with non- } \\
\text { pharmacological interventions? }\end{array}$ & 14 & 19.7 & 24 & 33.8 & 8 & 11.3 & 8.522 & .014 \\
\hline $\begin{array}{l}\text { 7. Were nursing practices helpful in relieving nausea and vomiting you } \\
\text { experienced due to disease? }\end{array}$ & 23 & 32.4 & 18 & 25.4 & 2 & 2.8 & 16.791 & .000 \\
\hline $\begin{array}{l}\text { 7A. Did your nausea-vomiting complaint decrease or disappear with } \\
\text { drug applications? }\end{array}$ & 24 & 33.8 & 12 & 16.9 & - & - & 4.000 & .046 \\
\hline $\begin{array}{l}\text { 7B. Did your nausea-vomiting complaint decrease or disappear with } \\
\text { non-pharmacological interventions? }\end{array}$ & 12 & 16.9 & 13 & 18.3 & 4 & 5.6 & 5.034 & .081 \\
\hline $\begin{array}{l}\text { 8. Were nursing practices helpful in overcoming oral problems you had } \\
\text { due to your illness? }\end{array}$ & 18 & 25.4 & 18 & 25.4 & - & - & .000 & 1.000 \\
\hline 8A. Did oral problems decrease or disappear with drug applications? & 14 & 21.1 & 10 & 14.1 & 3 & 4.2 & 7.786 & 0.020 \\
\hline $\begin{array}{l}\text { 8B. Did oral problems decrease or disappear with non-pharmacological } \\
\text { interventions? }\end{array}$ & 15 & 21.1 & 10 & 14.1 & - & - & 1.000 & 0.317 \\
\hline 10. Are you provided explanatory information about care by nurses? & 36 & 50.7 & 27 & 38.0 & 2 & 2.8 & 28.646 & .000 \\
\hline $\begin{array}{l}\text { 11. Do you think that you have been informed by the nurse about the } \\
\text { examinations to be performed about the disease? }\end{array}$ & 33 & 46.5 & 31 & 43.7 & 2 & 2.8 & 27.364 & .000 \\
\hline $\begin{array}{l}\text { 12. Is information provided by the nurse before and after the drug } \\
\text { applications performed? }\end{array}$ & 33 & 46.5 & 30 & 42.3 & 2 & 2.8 & 26.985 & .000 \\
\hline 13. Do you think nurses are sincere to you in care practices? & 32 & 45.1 & 22 & 31.0 & 6 & 8.5 & 17.200 & .000 \\
\hline $\begin{array}{l}\text { 14. Do you think that nurses communicate effectively with you during } \\
\text { their care practices? }\end{array}$ & 29 & 40.8 & 32 & 45.1 & 6 & 8.5 & 18.119 & .000 \\
\hline 15. Are nurses attentive to protect privacy during care practices? & 35 & 49.3 & 29 & 40.8 & 2 & 2.8 & 28.091 & .000 \\
\hline 16. Can you talk to nurses when you feel psychologically distressed? & 21 & 29.6 & 19 & 26.8 & 18 & 25.4 & .241 & .886 \\
\hline $\begin{array}{l}\text { 17. Is the participation of your family in nursing care practices } \\
\text { ensured? }\end{array}$ & 22 & 31.0 & 22 & 31.0 & 5 & 7.0 & 11.796 & .003 \\
\hline
\end{tabular}

$x^{2}$ : Chi-square test

\section{Discussion}

Intensive care units and the mechanical ventilation support treatment applied to cause some physiological changes in patients. Due to the negative effects of these health problems experienced, individuals become dependent on activities of daily living [ADL] and need someone else's help. Inadequacy in activities of daily living is evaluated by the criteria such as respiration, nutrition, excretion, movement, performing self-care, bathing, dressing, using phone, shopping, doing household chores, and taking own medicine. To be connected to a ventilator causes patients to be unable to meet these needs on their own. The patients with this condition are considered to be semi-dependent or fully dependent within the scope of their needs. The care needs of the dependent, semi-dependent, and independent patients are different from each other, and their levels of dependence should be first determined while planning nursing care [10]. In this study, it was determined that the levels of dependency of the patients were semi-dependent and that they needed support for personal needs such as bathing and toilet needs. In a similar study carried out by Yazıc1 and Kalayc1 [10], it was determined that $26.5 \%$ and $36.3 \%$ of the patients were fully dependent and semi-dependent, respectively, on bathing; and when the distinction was made by gender, it was determined that $33.3 \%$ of female patients and $22.2 \%$ male patients were dependent in meeting the need for bathing. In the same study, concerning meeting the need for a toilet, it was determined that $28.4 \%$ of the patients were fully dependent, and $33.3 \%$ of women and $25.4 \%$ of men were dependent according to gender. Similarly, in the study carried out by Akca et al. [11], it was determined that $6.3 \%$ of the patients were fully dependent and $15.7 \%$ of them were semi-dependent in activities of daily living. In the study carried out by Tasdelen and Ates [12], it was 
determined that four out of ten patients were fully dependent on bathing while four of them were fully dependent on performing excretion activity. According to these results, the vast majority of patients receiving ventilator support treatment need help in meeting the need for bathing. Help levels vary at full or semidependent levels according to the prognosis of patients. High levels of dependence of women than men are thought to be because female patients fear falling during bathing. Similarly, research results indicated that the patients were semi-dependent or fully dependent on meeting their toilet needs. The fact that the levels of dependence of women are high and they need more help is due to the difference in the anatomic structure.

Along with the physiological changes observed in intensive care units, invasive procedures such as mechanical ventilators and catheters may lead to physical limitations and psychological problems in patients. Patients may experience loneliness and isolation because they cannot be with family members and friends and cannot maintain their daily life habits. Furthermore, they also have anxiety due to the sounds of monitor systems, ventilators, fluid and/or drug infusion pumps in the intensive care setting and require psychological support at varying degrees. Therefore, establishing effective communication with patients and informing them before each application will comfort both the patient and their relatives. Indeed, it was determined that the patients participating in this study received sufficient information about their diseases and the practices performed by the nurses who provided care. In the questions related to the rating of care, it was determined that the item "Do you think that nurses communicate effectively with you during their care practices?" was answered as "moderately". In the study carried out by Kumcagiz et al. [13], it was indicated that communication was an important care tool in treatment in the periods of disease during which people are dependent, and it was determined that nurses' effective communication with the individual for whom they provided care, and with their family increased the quality of care positively. Similarly, Avsar and Kasıkc1 [14] also indicated that effective communication with the patient and his/ her family increased the quality of nursing care. In the same study, significant differences were found in the communication skills with the patients and their families of the nurses who were working in clinics such as outpatient clinics where there is less care, had high education level and average age, were married, had children and a working period of 20 years and more. In the study carried out by Dunsford [15], effective communication positively affected patient care in emergency and intensive care units where information flow between the medical team and the patient-family is active. According to the study carried out by Dilek et al. [16], the patients with mechanical ventilator support are the group experiencing communication difficulties. It is observed that these patients experience anxiety, fear, stress, loss of consciousness and control due to their inability to communicate. In the same study, it was indicated that eye contact, yes/no questions, facial expressions, paper-pencil, various signs, and shapes should be used in communication with the patients with mechanical ventilation support. In the study of Tosun et al. [17], communication with lip movements was reported to be a form of communication commonly used by patients on ventilation support. In the study carried out by Patak et al., it was determined that the communication board developed to minimize communication barriers in patients whose mechanical ventilation support terminated contributed to establishing communication in $69 \%$ of the patients.
According to the study, it was determined that the patients relied on the nursing care provided. In a similar study carried out by Soyuk et al. [18], it was determined that the patients generally relied on physicians, nurses, and staff working in intensive care units, found the treatment and care sufficient, could ask questions to them, and were satisfied with the intensive care setting and healthcare workers. In the study carried out by Hindistan et al. [19], care satisfactions were evaluated and patients were reported to be moderately satisfied. In the study carried out by Sekmen and Hatipoglu [20], it was determined that the sense of trust of $63.4 \%$ of the patients treated in intensive care units was due to the importance that the health team attached to care services. In the study carried out by Stein-Parbury and McKinley [21], the patients receiving treatment in intensive care units described nurses as the individuals who provide care, constantly monitor the patient, support while performing their self-care and reduce their fear and anxiety, and they stated that they relied on nurses.

It was determined that the item "Can you talk to nurses when you feel psychologically distressed?" was mostly answered as "Low", concerning the grading of care of patients participating in the study. The patients receiving mechanical ventilation support treatment in intensive care units frequently have communication problems. However, in the study carried out by Korhan et al. [22], it was determined that there was no numerical similarity between the patients who had communication problems and the patients receiving mechanical ventilation treatment. In the same study, it was determined that nurses did not pay attention to the communication problems experienced with the patients, did not provide sufficient communication, and ignored the communication efforts of the patients. Following these studies, nurses should give time to non-sedated or extubated patients receiving mechanical ventilation support treatment to express themselves, and they should support them for communication.

It was determined that the patients participating in the study largely answered "Yes" to the question "Were nursing practices helpful in relieving the pain you experienced due to your illness?". According to the study carried out by Simsek et al. [23], the catheters used, drains, invasive-noninvasive ventilation methods, aspiration, dressing changes, treatment, and care applications, position changes, pressure sores, and infections due to lying in the same position for a long time, in addition to the illnesses of the patients receiving treatment in intensive care units, cause pain. Furthermore, in the same study, it was indicated that the changes in consciousness due to the use of sedation prevented the evaluation of pain. The presence of pain in patients restricts the activities of daily living and causes them to remain inactive. On the other hand, in the study carried out by Payen et al. [24], it was determined that the behavioral pain scale including the parameters of facial expression, upper extremity movements, and compliance with mechanical ventilation were effective in patients under sedation undergoing mechanical ventilation support treatment was effective in evaluating the effectiveness of analgesia applied to patients, and it was adopted by nurses. In the study carried out by Aslan and Karadag [25], pain caused nurses in intensive care units to feel the responsibility for thinking and feeling instead of the patient and prolonged the healing process by negatively affecting the quality of care. Intensive care nurses have important roles in identifying and relieving pain by closely monitoring the patients since they are the team members who spend the most time with the patients. In the study carried out by Woo et al. [26], it was determined that pain was associated with the socio-economic condition of the patient. It was determined that people with poor 
socio-economic conditions and low educational levels had more pain in advanced age. In the study carried out by Simsek et al. [23], it was determined that the incidence of pain was higher in patients with high educational levels and more chronic diseases. In the same study, being a woman, advanced age, and chronic diseases were determined as important risk factors for pain. In the study carried out by Jakobsson et al. [27], it was determined that the incidence of pain was higher in the patients who were dependent on activities of daily living. In the study carried out by Reyes-Gibby et al. [28], it was indicated that pain affected the activities of daily living and caused activity limitation. The presence of pain in intensive care units is questioned by pain scales, and these studies show parallelism with the results of the research.

It was determined that the patients participating in the study answered positively to the question "Is the participation of your family in nursing care practices ensured?". Hill indicated that the vast majority of nurses included the family of patients while providing care. In the study carried out by Gurkan [29], it was determined that the most needed issue of patient relatives was to be with their patients and to participate in their care. These studies support the research results.

Nurses play an active role in the selection of correct care tools and products and the determination of the frequency of oral care by evaluating oral mucosa daily in patients receiving mechanical ventilation support treatment. Effective oral care provided significantly decreases the formation of ventilatorassociated pneumonia [VAP] in the patient. It was determined that the patients participating in the study answered positively to the question "Were nursing practices helpful in overcoming oral problems you had due to your illness?". In the study carried out by Aygin et al. [30], continuous opening mouth due to endotracheal tube used during mechanical ventilation treatment, inability to receive drugs and nutrients orally, disruption of tissue integrity caused by ligaments, plasters used for fixation of endotracheal tube led to the formation of dental plaque, periodontal diseases, bad breath and stomatitis in patients. In the study carried out by $\mathrm{Li}$ et al. [31], it was determined that the oral care provided with antiseptics such as chlorhexidine and povidone-iodine significantly reduced the formation of VAP in patients. In the study carried out by Par et al. [32], it was determined that VAP occurred as a result of aspiration of colonized bacteria in the oral cavity and dental plaques of the patients receiving mechanical ventilation support treatment, and therefore, the oral care provided with chlorhexidine significantly decreased the incidence of VAP. In addition, it was stated that the care given by the nurses regarding oral care significantly reduced the VAP formation. The results obtained from the studies support this study.

\section{Conclusion}

According to the study, there is a need to increase nurses' levels of knowledge about determining the care needs of patients receiving mechanical ventilation support treatment and meeting these needs. For this purpose, the knowledge of intensive care nurses should be strengthened by using visual learning techniques and simulation application methods, in addition to relevant theoretical training.

\section{Limitations}

There is a need to increase nurses' levels of knowledge about determining the care needs of patients receiving mechanical ventilation support treatment and meeting these needs.

Nurses should be informed about the importance of communicating with family members and patients during care practices.

Semi-dependent patients should be explained how to perform the care needs for which they need support.

Nurses should be supported in the development and implementation of care practices and the importance of care practices should be emphasized with frequent training.

The latest technological developments for care should be followed and cooperation should be ensured with the hospital administration to use these innovations in the field.

Disclosures: There is no conflict of interest for all authors.

\section{Acknowledgements: None.}

\section{Funding: None.}

Ethical considerations: Ethical issues [Including plagiarism, informed consent, misconduct, data fabrication and/or falsification, double publication and/or submission, redundancy, etc.] have been completely observed by the authors.

\section{References}

1. Turkmen E. Invasive mechanical ventilation and patient care for mechanical ventilation. JERN. 2005; 2(2):22-29. https://jer-nursing.org/ en/invasive-mechanical-ventilation-and-care-of-the-patient-with-mechanical-ventilation-1313066

2. Glaser K, Wright CJ. Indications for and Risks of Noninvasive Respiratory Support. Neonatology. 2021; (118.4):1-9. https://doi. org $/ 10.1159 / 000515818$

3. Ugur YL, Gökmen N. Tele-Intensive Care and the Current Situation in Turkey, Opportunities, Restrictions. Turk J Intensive Care, 2021; 19: 54-61. https://doi.org/10.4274/tybd.galenos.2021.96530

4. Kaplan T, Han S. Historical development of mechanical ventilators. Bulletin of Thoracic Surgery. 2014;5(3): 147-150. https://doi. org/10.5152/tcb.2014.0244

5. Ucgun I. Complications of mechanical ventilation. J. Intensive Care. 2008; 8(1):44-59. http://yogunbakimdergisi.org/managete/fu_ folder/2008-01/2008-8-1-044-059.pdf

6. Bozkurt G. Preventing ventilator-associated pneumonia in intensive care unit. Journal of Intensive Care Nursing. 2010;14(1):20-25.

7. Tagrikul H, Memis D, Inal MT, Turan N. Investigation of ventilator associated pneumoniae in intensive care patients. $J$ Turk Soc Intens Care. 2016; 14:28-38. https://doi.org/10.4274/tybdd.306022

8. Arık G, Varan H, Yavuz B, Karabulut B, Cankurtaran M. Validation of katz index of independence in activities of daily living in turkish older adults. Arch Gerontol Geriatr. 2015; 61: 344-350. https://doi.org/10.1016/j.archger.2015.08.019

9. Civi S, Tanrikulu MZ. An epidemiological study to determine the prevalence of chronic diseases and dependence and physical deficiency levels in the elderly. Turkish Journal of Geriatrics. 2000;3:85-90. http://geriatri.dergisi.org/uploads/pdf/pdf_TJG_40.pdf 
10. Yazıcı S, Kalaycı I. Evaluation of activities of daily life in elderly patients. SDU-JESD 2015;3(3):385-390. https://dergipark.org.tr/tr/ download/article-file/195477

11. Akca SD, Saracli O, Emre U, Atasay N, Gudul S, Barut BO, Atasoy HT. Relationship of cognitive functions with daily living activities, depression, anxiety and clinical variables in hospitalized elderly patients. Archives of Neuropsychiatry. 2014; 51: 267-274. https://doi. org/10.4274/npa.y7053

12. Tasdelen P, Ates M. Evaluation of the care needs of patients who need home care and burden of caregivers. HEAD.2012; 9 (3): $22-29$. https://www.onlinemakale.com/home/jvi.asp?pdir=kuhead\&plng=tur\&un=KUHEAD-68442

13. Kumcagiz H, Y1lmaz M, Celik S, Avc1 I. Communication skills of nurses: The case of samsun. Dicle MJ. 2011;38[1]:49-56. http://www. diclemedj.org/upload/sayi/13/Dicle\%20Med\%20J-01245.pdf

14. Avsar G, Kasikc1 M. Emotional intelingence levels of students of nursing college. Journal of Anatolia Nursing and Health Sciences. 2010;13:1-6. https://dergipark.org.tr/tr/download/article-file/29503

15. Dunsford J. Structured Communication improves patient safety with bar. NWH. 2009; 5:386-390. https://doi.org/10.1111/j.1751486X.2009.01456.X

16. Dilek F, Bitek D, Erol O. Common problems in elderly patients receiving intensive care treatment and nursing care. Journal of Intensive Care Nursing. 2015;19[1]:29-35. https://dergipark.org.tr/tr/pub/ybhd/issue/34951/403946

17. Tosun N, Yava A, Unver U, Akbayrak N, Hatipoglu S. Experience of patients on prolonged mechanical ventilation: a phenomenological study. J Med Sci. 2009;29(3):648-658. file:///C:/Users/gamze.temiz/Downloads/tipbil29-3-13.pdf

18. Soyluk S, Ore B, Yurugen B. Measurement of patient satisfaction in the intensive care unit of the first and emergency department of Istanbul university medical school. Journal of Intensive Care Nursing. 2001; 5:12-15. https://dergipark.org.tr/en/download/article-file/260034

19. Hindistan S, Nural N, Ozturk H. Experiences of inpatients in the intensive care unit. Journal of Intensive Care Nursing. 2009;13[1]:40-46. https://dergipark.org.tr/tr/download/article-file/260115

20. Sekmen K, Hatipoglu S. The Effects of intensive care unit technological environment on patient and family. Journal of Intensive Care Nursing. 1999; 3:22-26. https://dergipark.org.tr/tr/download/article-file/259967

21. Stein-Parbury J, McKinley S. Patient's experiences of being in an intensive care unit: a select literature review. Am J Crit Care. 2000; 9: 20-27. https://doi.org/10.4037/ajcc2000.9.1.20

22. Korhan E. Mekanik the role of the nurse in sedation management in patients with ventilation support. Journal of Intensive Care Nursing. 2012. https://dergipark.org.tr/tr/download/article-file/260152

23. Simsek T, Yumin E, Ozturk A, Sertel M, Yumin M. The relationship between pain, health status, mobility, and activity level in elderly people living in a home environment. Turk J Phys Med Rehab. 2011; 57:216-220. https://doi.org/10.4274/tftr.78557

24. Payen J., Bosson J, Chanques G, Mantz J, Labarere J. Pain assessment is associated with decreased duration of mechanical ventilation in the intensive care unit. Anesthesiology. 2009;111(6):1308-16. https://doi.org/10.1097/ALN.0b013e3181c0d4f0

25. Aslan F, Karadag S. Pain: an 1ssue that gives responsibility, essentiality feeling and thinking on the behalf of the patient to nurse at intensive care unit. Journal of Intensive Care Nursing. 2007;11(2):89-95. https://dergipark.org.tr/tr/download/article-file/260095

26. Woo J, Levng J, Lou E. Prevalence and correlates of musculoskeletal pain in Chinese elderly and the impact on 4-year physical function and quality of life. Public Health. 2009; 123:549-556. https://doi.org/10.1016/j.puhe.2009.07.006

27. Jakobsson U, Hallberg IR, Westergren A. Pain management in elderly persons who require assistance with activities of daily living is a comparison of those living at home with those in special accommodations. Ever J Pain. 2004; 8:335. https://doi.org/10.1016/j. ejpain.2003.10.007

28. Reyyes-Gibby CC, Aday L, Cleeland C. Impact of Pain on Self-Rated Health in the Community-Dwelling Older Adults. Pain . 2002; 95:75-82. https://doi.org/10.1016/S0304-3959(01)00375-X

29. Gurkan A. Holistic Approach: Family members with ICU patients. Journal of Intensive Care Nursing. 2009;13[1]:1-5. https://dergipark. org.tr/tr/pub/ybhd/issue/26484/278742

30. Aygin D, Cetin B. Role of the prevention of oral care ventilator-associated pneumonia. Sakarya Medical Journal. $2017 ; 7[1]: 74-78$. https://dergipark.org.tr/tr/pub/johr/issue/26948/283264

31. Li L, Ai Z, Li L, Zheng X, Jie L. Can routine oral care with antiseptics prevent ventilator-associated pneumonia in patients receiving mechanical ventilation? an updated meta-analysis from 17 randomized controlled trials. Int J Clin Exp. Med. 2015; 8(2):1645-1702.

32. Par M, Badovinac A, Plancak D. Oral hygiene is an important factor for the prevention of ventilator-associated pneumonia. Acta Clin Croat. 2014; 53(1):72-80 